\title{
A Valuable Advance in the Synthesis of Carbohydrate Based Anticancer Vaccines Through Extended Cycloaddition Chemistry
}

\author{
Qian Wan ${ }^{1}$, Jiehao Chen ${ }^{1}$, Gong Chen ${ }^{1}$, Samuel J. Danishefsky ${ }^{1,2, *}$
}

${ }^{1}$ Laboratory for Bioorganic Chemistry, Sloan-Kettering Institute for Cancer Research, 1275 York Avenue, New York, New York 10021,

${ }^{2}$ Department of Chemistry, Columbia University, Havemeyer Hall, 3000 Broadway, New York, New York 10027

E-mail: s-danishefsky@ski.mskcc.org

\section{Contents List of the Supporting Information:}

S1 Content and General Procedure for HPLC and LCMass

S2 Synthesis of compound 3

S2-S3 Synthesis of compound 4

S3 Synthesis of compound 6

S4 Synthesis of compound 8

S4-S5 Synthesis of compound 9

S5-S6 Synthesis of compound 10

S6-S7 Synthesis of compound 11

S7 Synthesis of compound 12

S7-S8 Synthesis of compound 13

S8-S9 Synthesis of compound 14 (LCMass Spectrum: Figure 1 and 2)

S10-S11 LCMass of Synthesis of compound 15 (Figure 3, 4 and 5)

S12 Synthesis of compound 16 (LCMass Spectrum: Figure 6)

S13-S15 Synthesis of compound 17 (LCMass Spectrum: Figure 7, 8, and 9)

S15 Synthesis of compound 19

S16-S41 NMR spectra for all new compounds

\section{General Procedure for HPLC and LCMass}

All separations involved a mobile phase of $0.05 \%$ TFA in water (solvent A)/).00425\% TFA in acetonitrile (solvent B). 


\section{Compound 3: FmocHN-Tn(OAc) $)_{3}-\mathrm{CONH}-\left(\mathrm{CH}_{2}\right)_{3}-\mathrm{N}_{3}$

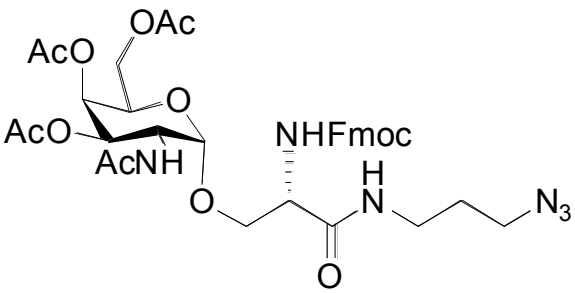 \\ $\mathrm{C}_{35} \mathrm{H}_{42} \mathrm{~N}_{6} \mathrm{O}_{12}$ \\ Exact Mass: 738.29 \\ Mol. Wt.: 738.74}

To a solution of Tn-acid $(1,100.0 \mathrm{mg}, 0.15 \mathrm{mmol})$ in $\mathrm{DMF}-\mathrm{CH}_{2} \mathrm{Cl}_{2}(1: 1,1.5 \mathrm{~mL})$ at -10 ${ }^{\circ} \mathrm{C}$ was added HOBt $(32.4 \mathrm{mg}, 0.24 \mathrm{mmol})$ followed by EDCI $(38.0 \mathrm{mg}, 0.20 \mathrm{mmol})$. The reaction mixture was stirred at $0{ }^{\circ} \mathrm{C}$ for $30 \mathrm{~min}$ and then $\mathrm{H}_{2} \mathrm{~N}-\left(\mathrm{CH}_{2}\right)_{3}-\mathrm{N}_{3}(15.3 \mathrm{mg}, 16.0$ $\mu \mathrm{L}, 0.15 \mathrm{mmol}$ ) was added. After stirring for overnight, the reaction mixture was diluted with EtOAc, washed with brine- $\mathrm{H}_{2} \mathrm{O}(1: 1)$. The organic phase was dried with $\mathrm{Na}_{2} \mathrm{SO}_{4}$, concentrated in vacuo. The residue was purified by silica gel column chromatography (3$5 \% \mathrm{MeOH}$ in $\left.\mathrm{CH}_{2} \mathrm{Cl}_{2}\right)$ to give the desired amide $(3,103.6 \mathrm{mg}, 0.14 \mathrm{mmol}, 92 \%)$ as a white foam. $[\alpha]_{\mathrm{D}}{ }^{23}=63.8\left(c 1.16, \mathrm{CHCl}_{3}\right)$; IR 3318, 2929, 2099, 1748, 1660, 1537, 1371, 1236, 1051, 761, and $741 \mathrm{~cm}^{-1} ;{ }^{1} \mathrm{H} \mathrm{NMR}\left(500 \mathrm{MHz}, \mathrm{CDCl}_{3}\right): \delta 7.75(\mathrm{~d}, 2 \mathrm{H}, J=7.5 \mathrm{~Hz})$, 7.57 (d, $2 \mathrm{H}, J=7.2 \mathrm{~Hz}), 7.39$ (t, $2 \mathrm{H}, J=7.4 \mathrm{~Hz}), 7.30$ (t, $2 \mathrm{H}, J=7.4 \mathrm{~Hz}), 6.52$ (br, 1 $\mathrm{H}), 6.01(\mathrm{~d}, 1 \mathrm{H}, J=9.5 \mathrm{~Hz}), 5.72(\mathrm{~m}, 1 \mathrm{H}), 5.32(\mathrm{~d}, 1 \mathrm{H}, J=2.7 \mathrm{~Hz}), 5.03(\mathrm{dd}, 1 \mathrm{H}, J=$ $3.0,11.3 \mathrm{~Hz}), 4.83(\mathrm{~d}, 1 \mathrm{H}, J=2.8 \mathrm{~Hz}), 4.60-4.40(\mathrm{~m}, 3 \mathrm{H}), 4.32(\mathrm{br}, 1 \mathrm{H}), 4.20(\mathrm{t}, 1 \mathrm{H}, J$ $=6.4 \mathrm{~Hz}), 4.09(\mathrm{t}, 1 \mathrm{H}, J=6.4 \mathrm{~Hz}), 4.02(\mathrm{~d}, 2 \mathrm{H}, J=6.3 \mathrm{~Hz}), 3.86(\mathrm{~m}, 2 \mathrm{H}), 3.41-3.28(\mathrm{~m}$, $4 \mathrm{H}), 2.14(\mathrm{~s}, 3 \mathrm{H}), 1.98(\mathrm{~s}, 3 \mathrm{H}), 1.97(\mathrm{~s}, 3 \mathrm{H}), 1.94(\mathrm{~s}, 3 \mathrm{H}) .{ }^{13} \mathrm{C}$ NMR $(125 \mathrm{MHz}$, $\left.\mathrm{CDCl}_{3}\right): \delta 170.9,170.6,170.4,170.3,169.3,143.6,143.5,141.3,127.9,127.1,124.9$, 120.1, 99.1, 69.5, 68.3, 67.2, 67.1, 61.8, 54.7, 49.4, 47.6, 47.1, 37.5, 28.4, 23.1, 20.73, 20.71 and 20.66; MS (EI) $\mathrm{m} / z$ 761.5 [M+ Na] $]^{+}$; HRM calcd for $\mathrm{C}_{35} \mathrm{H}_{43} \mathrm{~N}_{6} \mathrm{O}_{12}[\mathrm{M}+\mathrm{H}]^{+}$ 739.2939, found 739.2935.

\section{Compound 4: FmocHN-STn(OAc) $)_{5}-\mathrm{CONH}-\left(\mathrm{CH}_{2}\right)_{3}-\mathrm{N}_{3}$}

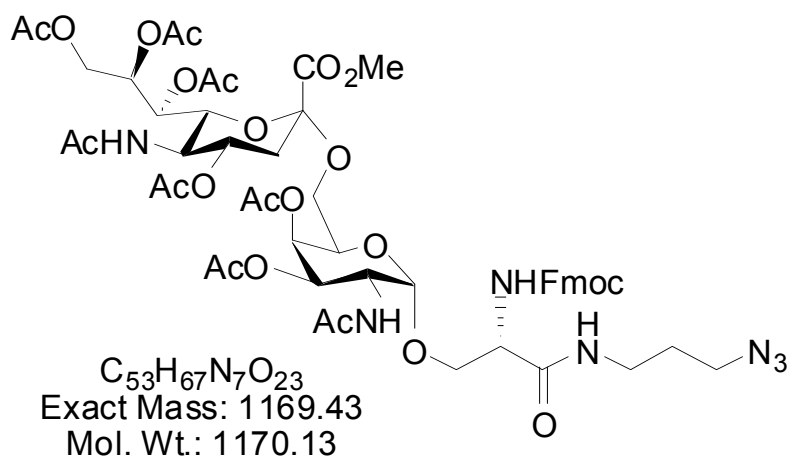

To a solution of STn-acid $2(22.0 \mathrm{mg}, 20.2 \mu \mathrm{mol})$ in DMF- $\mathrm{CH}_{2} \mathrm{Cl}_{2}(1: 1,1.0 \mathrm{~mL})$ at $0{ }^{\circ} \mathrm{C}$ was added HOBt $(4.1 \mathrm{mg}, 30.3 \mu \mathrm{mol})$ followed by EDCI $(5.8 \mathrm{mg}, 30.3 \mu \mathrm{mol})$. The reaction mixture was stirred at $0{ }^{\circ} \mathrm{C}$ for $30 \mathrm{~min}$ and then $\mathrm{H}_{2} \mathrm{~N}-\left(\mathrm{CH}_{2}\right)_{3}-\mathrm{N}_{3}(2.2 \mathrm{mg}, 20.2$ $\mu \mathrm{mol})$ was added. The reaction mixture was warmed to $\mathrm{rt}$ and stirred at $\mathrm{rt}$ for $2 \mathrm{~h}$ before it 
was concentrated in vасио. The resultant reaction residue was purified by silica gel column chromatography (3-5\% $\mathrm{MeOH}$ in $\mathrm{CH}_{2} \mathrm{Cl}_{2}$ ) to give the desired amide 4 (18.5 mg, $15.8 \mu \mathrm{mol}, 78 \%)$ as a white foam. $[\alpha]_{\mathrm{D}}^{23}=31.4\left(c 0.88, \mathrm{CHCl}_{3}\right)$; IR 3317, 2903, 2097, 1723, 1643, 1386, 1250, $1101 \mathrm{~cm}^{-1} ;{ }^{1} \mathrm{H}$ NMR (500 MHz, $\left.\mathrm{CDCl}_{3}\right): \delta 7.77$ (d, $2 \mathrm{H} \mathrm{J}=7.5$ $\mathrm{Hz}$ ), 7.60 (d, $2 \mathrm{H}, J=7.3 \mathrm{~Hz}), 7.41(\mathrm{t}, 2 \mathrm{H}, J=7.4 \mathrm{~Hz}), 7.32(\mathrm{t}, 2 \mathrm{H}, J=7.3 \mathrm{~Hz}), 5.44(\mathrm{~d}$, $1 \mathrm{H}, J=2.1 \mathrm{~Hz}), 5.30(\mathrm{~m}, 2 \mathrm{H}), 5.09(\mathrm{~m}, 2 \mathrm{H}), 4.87(\mathrm{~m}, 2 \mathrm{H}), 4.56$ (ddd, $1 \mathrm{H}, J=3.6,9.7$, $11.5 \mathrm{~Hz}), 4.48(\mathrm{~m}, 1 \mathrm{H}), 4.44(\mathrm{~m}, 1 \mathrm{H}), 4.35(\mathrm{~m}, 1 \mathrm{H}), 4.22(\mathrm{t}, 1 \mathrm{H}, J=6.8 \mathrm{~Hz}), 4.17(\mathrm{t}, 1$ $\mathrm{H}, J=6.6 \mathrm{~Hz}), 4.11(\mathrm{dd}, 1 \mathrm{H}, J=4.6,12.5 \mathrm{~Hz}), 4.03(\mathrm{~m}, 2 \mathrm{H}), 3.96(\mathrm{~m}, 1 \mathrm{H}), 3.92(\mathrm{~m}, 1$ H), $3.77(\mathrm{~s}, 3 \mathrm{H}), 3.74(\mathrm{dd}, 1 \mathrm{H}, J=6.610 .5 \mathrm{~Hz}), 3.39(\mathrm{~m}, 5 \mathrm{H}), 2.52(\mathrm{dd}, 1 \mathrm{H}, J=4.7$, $12.9 \mathrm{~Hz}), 2.17$ (s, $3 \mathrm{H}), 2.11(\mathrm{~s}, 6 \mathrm{H}), 2.04$ (s, $3 \mathrm{H}), 2.02$ (s, $3 \mathrm{H}), 1.98$ (s, $3 \mathrm{H}), 1.96$ (s, 3 $\mathrm{H}), 1.80(\mathrm{~m}, 2 \mathrm{H}), 1.89(\mathrm{~s}, 3 \mathrm{H}), 1.21(\mathrm{~m}, 2 \mathrm{H}) ;{ }^{13} \mathrm{C} \mathrm{NMR}\left(125 \mathrm{MHz}, \mathrm{CDCl}_{3}\right): \delta 171.3$, $171.1,170.9,170.7,170.6,170.6,170.0,168.2$, 163.0, 144.0, 141.72 128.3, 127.5, 125.4, $120.5,99.7,99.3,73.0,70.4,69.2,69.0,68.9,67.8,67.6,67.6,63.7,62.6,53.3,49.8,49.7$, 48.1, 47.6, 37.9, 37.7, 36.9, 31.9, 29.0, 23.7 and 23.6; MS (EI) $m / z 1192.6[\mathrm{M}+\mathrm{Na}]^{+}$.

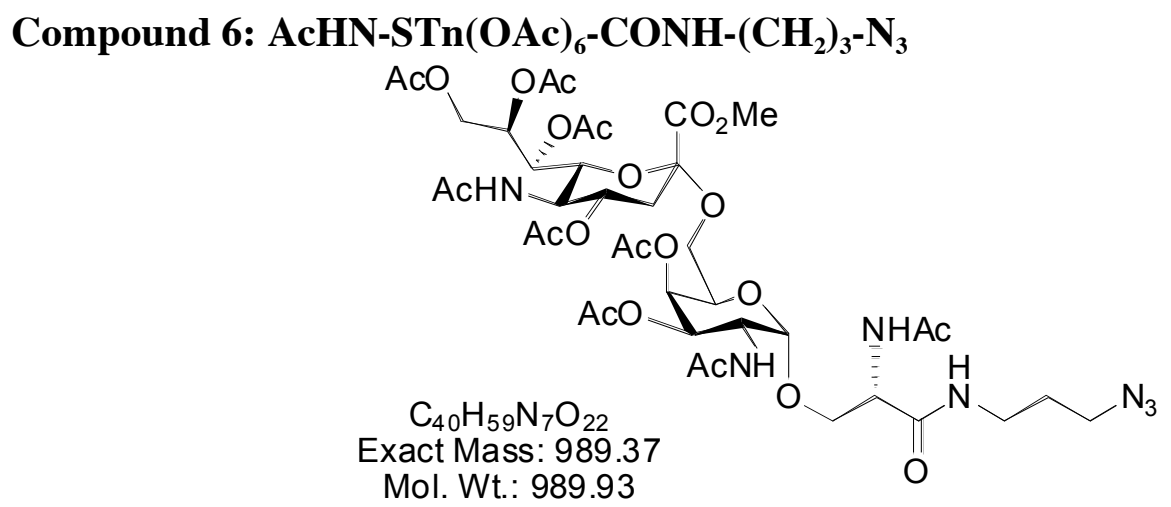

To a solution of compound $4(18.0 \mathrm{mg}, 15.4 \mu \mathrm{mol})$ in DMF $(2.0 \mathrm{~mL})$ was added $\mathrm{Et}_{2} \mathrm{NH}$ $(8.0 \mu \mathrm{L})$. The resultant reaction mixture was stirred at $\mathrm{rt}$ for $1 \mathrm{~h}$ before acetic anhydride $(10.0 \mu \mathrm{L})$ and $\mathrm{Et}_{3} \mathrm{~N}(8.0 \mu \mathrm{L})$ were added. After stirring at $\mathrm{rt}$ for $2 \mathrm{~h}$, the reaction mixture was concentrated in vасио and purified by silica gel column chromatography (EtOAc $100 \%$ to $10 \% \mathrm{MeOH}$ in $\mathrm{CH}_{2} \mathrm{Cl}_{2}$ ) to give the desired azide $(6,15.0 \mathrm{mg}, 15.1 \mu \mathrm{mol}, 98 \%$ over 2 steps) as a white foam. ${ }^{1} \mathrm{H}$ NMR $\left(500 \mathrm{MHz} \mathrm{CDCl}_{3}\right): \delta 6.85(\mathrm{t}, 1 \mathrm{H}, J=5.8 \mathrm{~Hz})$, $6.78(\mathrm{~d}, 1 \mathrm{H}, J=7.7 \mathrm{~Hz}), 6.19(\mathrm{~d}, 1 \mathrm{H}, J=9.7 \mathrm{~Hz}), 5.42(\mathrm{~d}, 1 \mathrm{H}, J=2.2 \mathrm{~Hz}), 5.31(\mathrm{~m}, 2$ H), $5.13(\mathrm{~m}, 1 \mathrm{H}), 5.09(\mathrm{dd}, 1 \mathrm{H}, J=3.2,11.3 \mathrm{~Hz}), 4.90(\mathrm{~m}, 1 \mathrm{H}), 4.84(\mathrm{~d}, 1 \mathrm{H}, J=3.6$ $\mathrm{Hz}), 4.68(\mathrm{~m}, 1 \mathrm{H}), 4.56(\mathrm{~m}, 1 \mathrm{H}), 4.37(\mathrm{dd}, 1 \mathrm{H}, J=2.6,12.3 \mathrm{~Hz}), 4.13(\mathrm{~m}, 3 \mathrm{H}), 4.08$ $(\mathrm{m}, 2 \mathrm{H}), 3.96(\mathrm{dd}, 1 \mathrm{H}, J=3.6,10.5 \mathrm{~Hz}), 3.88(\mathrm{dd}, 1 \mathrm{H}, J=5.2,10.5 \mathrm{~Hz}), 3.79(\mathrm{~s}, 3 \mathrm{H})$, $3.76(\mathrm{dd}, 1 \mathrm{H}, J=6.6,10.4 \mathrm{~Hz}), 3.35(\mathrm{~m}, 6 \mathrm{H}), 2.52(\mathrm{dd}, 1 \mathrm{H}, J=4.8,12.7 \mathrm{~Hz}), 2.17$ (s, 3 H), 2.15 (s, 3 H), 2.14 (s, 3 H), 2.09 (s, 3 H), 2.08 (s, 3 H), 2.07 (s, 3 H), 2.04 (s, 3 H), 2.03 (s, $3 \mathrm{H}), 2.01$ (s, $3 \mathrm{H}), 1.98$ (s, $3 \mathrm{H}), 1.89$ (s, $3 \mathrm{H}), 1.80(\mathrm{~m}, 2 \mathrm{H}), 1.21$ (m, $2 \mathrm{H})$; MS (EI) $m / z$ 1012.5 $[\mathrm{M}+\mathrm{Na}]^{+}$. 
Compound 8: AcHN-STn-CONH- $\left(\mathrm{CH}_{2}\right)_{3}-\mathrm{N}_{3}$

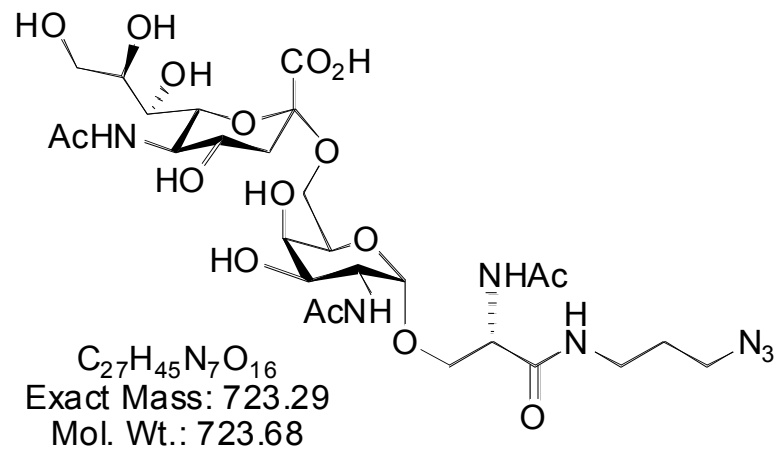

To a solution of compound AcHN-STn(OAc) $)_{6}-\mathbf{C O N H}-\left(\mathbf{C H}_{2}\right)_{3}-\mathbf{N}_{3}(15.0 \mathrm{mg}, 15.1 \mu \mathrm{mol})$ in $\mathrm{MeOH}(1.1 \mathrm{~mL})$ was added aqueous $\mathrm{NaOH}(0.1 \mathrm{~N}, 1.1 \mathrm{~mL})$ at $0{ }^{\circ} \mathrm{C}$. The resultant reaction mixture was warmed to $\mathrm{rt}$ and stirred at $\mathrm{rt}$ overnight before it was neutralized with Dowex and filtered. The crude reaction mixture was purified by RP-HPLC (5-25\% solvent B/solvent A over $20 \mathrm{~min}$.) to give the desired product $8(10.5 \mathrm{mg}, 14.6 \mu \mathrm{mol}$, $96 \%)$ as a white foam. ${ }^{1} \mathrm{H}$ NMR $\left(500 \mathrm{MHz}, \mathrm{D}_{2} \mathrm{O}\right): \delta 4.78(\mathrm{~d}, 1 \mathrm{H}, J=3.7 \mathrm{~Hz}), 4.44(\mathrm{~m}, 1$ $\mathrm{H}), 4.06(\mathrm{dd}, 1 \mathrm{H}, J=3.7,10.9 \mathrm{~Hz}), 4.05(\mathrm{dd}, 1 \mathrm{H}, J=3.7,11.1 \mathrm{~Hz}), 3.88(\mathrm{~m}, 4 \mathrm{H}), 3.79$ $(\mathrm{m}, 4 \mathrm{H}), 3.69(\mathrm{~m}, 3 \mathrm{H}), 3.57(\mathrm{~m}, 2 \mathrm{H}), 3.46(\mathrm{~d}, 1 \mathrm{H}, J=8.5 \mathrm{~Hz}), 3.23(\mathrm{~m}, 4 \mathrm{H}), 2.61$ (dd, $1 \mathrm{H}, J=4.7,12.5 \mathrm{~Hz}), 1.98(\mathrm{~s}, 3 \mathrm{H}), 1.95(\mathrm{~s}, 3 \mathrm{H}), 1.94(\mathrm{~s}, 3 \mathrm{H}), 1.69(\mathrm{~m}, 3 \mathrm{H}) ;{ }^{13} \mathrm{C} \mathrm{NMR}$ (125 MHz, $\left.\mathrm{D}_{2} \mathrm{O}\right): \delta 175.3,174.8,174.6,172.2,171.7,99.7,98.1,73.1,71.5,70.1,68.7$, $68.7,68.0,67.8,67.7,64.1,63.2,54.4,52.1,50.1,49.0,39.9,37.2,28.0,22.4,22.4$ and 22.1; MS (EI) $m / z, 724.3[\mathrm{M}+\mathrm{H}]^{+}$.

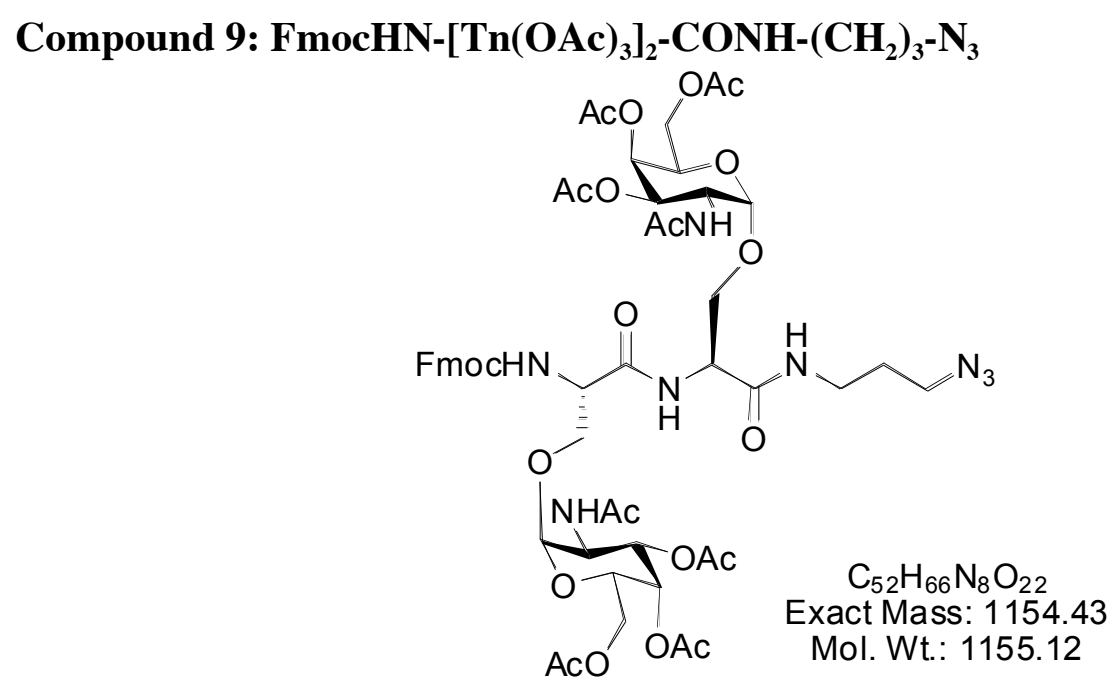

To a solution of FmocHN-Tn(OAc) $)_{3}$ - CONH- $\left(\mathbf{C H}_{2}\right)_{3}-\mathbf{N}_{3}(\mathbf{3}, 66.7 \mathrm{mg}, 90.0 \mu \mathrm{mol})$ in DMF $(1.5 \mathrm{~mL})$ was added diethylamine $(20.0 \mu \mathrm{L})$. The reaction mixture was stirred at room temperature for $3 \mathrm{~h}$, the solvents were removed by high vacuum. To a solution of Tn-acid $(\mathbf{1}, 62.3 \mathrm{mg}, 94.0 \mu \mathrm{mol})$ in DMF- $\mathrm{CH}_{2} \mathrm{Cl}_{2}(1: 1,1.0 \mathrm{~mL})$ at $-10{ }^{\circ} \mathrm{C}$ was added HOBT $(19.2$ 
$\mathrm{mg}, 0.14 \mathrm{mmol})$ followed by EDCI $(22.4 \mathrm{mg}, 0.12 \mathrm{mmol})$. The reaction mixture was stirred at $0{ }^{\circ} \mathrm{C}$ for $30 \mathrm{~min}$ and then was transferred to the solution of $\mathbf{H}_{2} \mathbf{N}-\mathbf{T n}(\mathbf{O A c})_{3^{-}}$ CONH- $\left(\mathrm{CH}_{2}\right)_{3}-\mathrm{N}_{3}$ in DMF- $\mathrm{CH}_{2} \mathrm{Cl}_{2}(1: 1,1.0 \mathrm{~mL})$ at room temperature. After stirring for 3 $h$, the reaction mixture was diluted with EtOAc, washed with brine- $\mathrm{H}_{2} \mathrm{O}$ (1:1). The organic phase was dried with $\mathrm{Na}_{2} \mathrm{SO}_{4}$, concentrated in vacuo. The residue was purified by silica gel column chromatography (3-5\% $\mathrm{MeOH}$ in $\mathrm{CH}_{2} \mathrm{Cl}_{2}$ ) to give the desired dimer (9, $92.0 \mathrm{mg}, 80.0 \mu \mathrm{mol}, 88 \%)$ as a white foam. $[\alpha]_{\mathrm{D}}{ }^{23}=75.7\left(c 1.12, \mathrm{CHCl}_{3}\right)$; IR 3312, 3069, 2937, 2099, 1748, 1652, 1538, 1450, 1371, $1249 \mathrm{~cm}^{-1} .{ }^{1} \mathrm{H}$ NMR (500 MHz, $\left.\mathrm{CDCl}_{3}\right): \delta$ $7.74(\mathrm{~d}, 2 \mathrm{H}, J=7.6 \mathrm{~Hz}), 7.55(\mathrm{~m}, 2 \mathrm{H}), 7.39(\mathrm{~m}, 2 \mathrm{H}), 7.29(\mathrm{~m}, 2 \mathrm{H}), 7.15(\mathrm{~d}, 1 \mathrm{H}, J=$ $7.3 \mathrm{~Hz}), 6.74(\mathrm{~m}, 1 \mathrm{H}), 6.60(\mathrm{~d}, 1 \mathrm{H}, J=8.3 \mathrm{~Hz}), 6.16(\mathrm{~d}, 1 \mathrm{H}, J=9.2 \mathrm{~Hz}), 6.01(\mathrm{~d}, 1 \mathrm{H}, J$ $=6.1 \mathrm{~Hz}), 5.32(\mathrm{~d}, 2 \mathrm{H}, J=1.4 \mathrm{~Hz}), 5.08(\mathrm{dd}, 1 \mathrm{H}, J=3.2,11.7 \mathrm{~Hz}), 5.05(\mathrm{dd}, 1 \mathrm{H}, J=$ 3.2, $11.7 \mathrm{~Hz}), 4.94(\mathrm{~m}, 1 \mathrm{H}), 4.85(\mathrm{~d}, 1 \mathrm{H}, J=3.4 \mathrm{~Hz}), 4.67(\mathrm{~m}, 1 \mathrm{H}), 4.53(\mathrm{~m}, 3 \mathrm{H}), 4.39$ $(\mathrm{dd}, 1 \mathrm{H}, J=6.4,10.1 \mathrm{~Hz}), 4.27(\mathrm{~m}, 1 \mathrm{H}), 4.18(\mathrm{t}, 1 \mathrm{H}, J=6.3 \mathrm{~Hz}), 4.11(\mathrm{t}, 1 \mathrm{H}, J=6.4$ Hz), 4.10-3.90 (m, 7 H), 3.70 (m, 2 H), 3.37 (m, 4 H), 2.14 (t, $2 \mathrm{H}, J=3.4$ Hz), 2.13 (s, 3 H), $2.12(\mathrm{~s}, 3 \mathrm{H}), 2.01(\mathrm{~m}, 1 \mathrm{H}), 1.99(\mathrm{~s}, 3 \mathrm{H}), 1.98(\mathrm{~s}, 1 \mathrm{H}), 1.96(\mathrm{~s}, 3 \mathrm{H}), 1.95(\mathrm{~s}, 3 \mathrm{H})$, $1.94(\mathrm{~s}, 3 \mathrm{H}), 1.92(\mathrm{~s}, 3 \mathrm{H})$ and $1.80(\mathrm{~m}, 2 \mathrm{H}) .{ }^{13} \mathrm{C}$ NMR $\left(125 \mathrm{MHz}, \mathrm{CDCl}_{3}\right): \delta 170.9$, $170.9,170.85,170.80,170.7,170.5,170.3,169.5,168.6,156.4,143.6,143.4,141.3$, $127.8,127.1,127.1,124.8,124.7,120.1,99.5,98.6,69.5,69.4,68.4,68.2,67.6,67.2$, 67.0, 66.9, 61.8, 61.7, 54.8, 53.8, 53.2, 49.3, 47.9, 47.5, 47.0, 31.7, 30.9, 29.3, 28.3, 23.1, 23.0, 20.7 and 20.7. MS (EI) $m / z$ 1177.6 [M+ Na $]^{+}, 1189.6[\mathrm{M}+\mathrm{Cl}]^{-}$.

\section{Compound 10: $\mathrm{FmocHN}-\left[\mathrm{Tn}(\mathrm{OAc})_{3}\right]_{3}-\mathrm{CONH}-\left(\mathrm{CH}_{2}\right)_{3}-\mathrm{N}_{3}$}

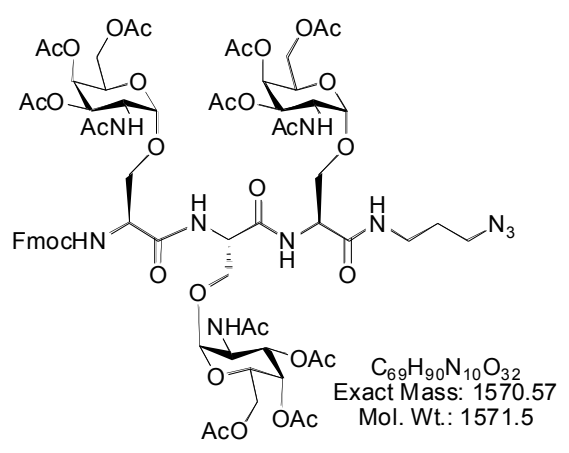

To a solution of FmocHN-[Tn(OAc) $\left.)_{3}\right]_{2}-\mathbf{C O N H}-\left(\mathbf{C H}_{2}\right)_{3}-\mathbf{N}_{3}(\mathbf{9}, 90.0 \mathrm{mg}, 78.0 \mu \mathrm{mol}, 1)$ in DMF $(1.5 \mathrm{~mL})$ was added diethylamine $(20.0 \mu \mathrm{L})$. The reaction mixture was stirred at room temperature for $1 \mathrm{~h}$, the solvents were removed by high vacuum. To a solution of Tn-acid $(1,53.7 \mathrm{mg}, 82.0 \mu \mathrm{mol})$ in $\mathrm{DMF}-\mathrm{CH}_{2} \mathrm{Cl}_{2}(1: 1,1.0 \mathrm{~mL})$ at $-10{ }^{\circ} \mathrm{C}$ was added $\mathrm{HOBt}$ (16.6 $\mathrm{mg}, 0.12 \mathrm{mmol})$ followed by EDCI $(19.4 \mathrm{mg}, 0.10 \mathrm{mmol})$. The reaction mixture was stirred at $0{ }^{\circ} \mathrm{C}$ for $30 \mathrm{~min}$ and then was transferred to the solution of $\mathbf{H}_{2} \mathbf{N}$ $\left[\mathbf{T n}(\mathrm{OAc})_{3}\right]_{2}-\mathbf{C O N H}-\left(\mathrm{CH}_{2}\right)_{3}-\mathbf{N}_{3}$ in $\mathrm{DMF}-\mathrm{CH}_{2} \mathrm{Cl}_{2}(1: 1,1.0 \mathrm{~mL})$ at room temperature. After stirring for $3 \mathrm{~h}$, the reaction mixture was diluted with EtOAc, washed with brine$\mathrm{H}_{2} \mathrm{O}$ (1:1). The organic phase was dried with $\mathrm{Na}_{2} \mathrm{SO}_{4}$, concentrated in vacuo. The residue was purified by silica gel column chromatography (3-5\% $\mathrm{MeOH}$ in $\mathrm{CH}_{2} \mathrm{Cl}_{2}$ ) to give the desired trimer $(\mathbf{1 0}, 111.0 \mathrm{mg}, 0.07 \mathrm{mmol}, 90 \%$ over 2 steps $)$ as a white foam. $[\alpha]_{\mathrm{D}}{ }^{24}=$ 103.3 (c 1.08, $\mathrm{CHCl}_{3}$ ); IR 3327, 3070, 2934, 2100, 1747, 1664, 1530, 1445, 1372, 1233 , 
1132, 1051, 915 and $734 \mathrm{~cm}^{-1} .{ }^{1} \mathrm{H}$ NMR (500 MHz, $\left.\mathrm{CDCl}_{3}\right): \delta 7.72(\mathrm{~d}, 2 \mathrm{H}, J=7.5 \mathrm{~Hz})$, $7.54(\mathrm{~d}, 2 \mathrm{H}, J=7.4 \mathrm{~Hz}), 7.37(\mathrm{t}, 2 \mathrm{H}, J=7.4 \mathrm{~Hz}), 7.27(\mathrm{t}, 2 \mathrm{H}, J=7.4 \mathrm{~Hz}), 7.14(\mathrm{~m}, 1 \mathrm{H})$, $7.04(\mathrm{~m}, 2 \mathrm{H}), 6.95(\mathrm{~d}, 1 \mathrm{H}, J=8.6 \mathrm{~Hz}), 6.56(\mathrm{~d}, 1 \mathrm{H}, J=8.9 \mathrm{~Hz}), 6.40(\mathrm{~d}, 1 \mathrm{H}, J=8.7$ $\mathrm{Hz}), 5.96(\mathrm{~d}, 1 \mathrm{H}, J=6.9 \mathrm{~Hz}), 5.35(\mathrm{~d}, 1 \mathrm{H}, J=2.5 \mathrm{~Hz}), 5.33(\mathrm{~s}, 2 \mathrm{H}), 5.14(\mathrm{dd}, 1 \mathrm{H}, J=$ $3.1,11.4 \mathrm{~Hz}$ ), 5.09 (dd, $1 \mathrm{H}, J=3.1,11.6 \mathrm{~Hz}), 5.05$ (dd, $1 \mathrm{H}, J=3.0,11.5 \mathrm{~Hz}), 4.93$ (d, 2 $\mathrm{H}, J=3.1 \mathrm{~Hz}), 4.89(\mathrm{~d}, 1 \mathrm{H}, J=2.8 \mathrm{~Hz}), 4.56-4.45(\mathrm{~m}, 5 \mathrm{H}), 4.45-4.30(\mathrm{~m}, 3 \mathrm{H}), 4.21-$ 4.15 (m, $4 \mathrm{H}), 4.10-4.03$ (m, $3 \mathrm{H}), 4.03-4.0(\mathrm{~m}, 2 \mathrm{H}), 4.0-3.85(\mathrm{~m}, 3 \mathrm{H}), 3.83-3.80$ (m, 3 $\mathrm{H}), 3.73(\mathrm{t}, 1 \mathrm{H}, J=8.6 \mathrm{~Hz}), 3.68(\mathrm{t}, 1 \mathrm{H}, J=8.5), 3.40-3.15(\mathrm{~m}, 4 \mathrm{H}), 2.12(\mathrm{~s}, 3 \mathrm{H}), 2.11$ (s, $3 \mathrm{H}), 2.10(\mathrm{~s}, 3 \mathrm{H}), 2.01-1.97(\mathrm{~s} x \mathrm{6}, 18 \mathrm{H}), 1.94(\mathrm{~s}, 3 \mathrm{H}), 1.93(\mathrm{~s}, 3 \mathrm{H}), 1.92(\mathrm{~s}, 3 \mathrm{H})$, $1.89(\mathrm{~s}, 3 \mathrm{H})$ and $1.75(\mathrm{~m}, 2 \mathrm{H}) .{ }^{13} \mathrm{C} \mathrm{NMR}\left(125 \mathrm{MHz}, \mathrm{CDCl}_{3}\right): \delta 171.6,171.2,171.1$, 171.0, 170.8, 170.6, 170.6, 170.5, 170.3, 169.8, 168.9, 155.9, 143.6, 143.4, 141.3, 127.8, 127.0, 124.9, 124.8, 120.0, 98.6, 98.2, 98.1, 69.5, 68.8, 68.4, 67.9, 67.8, 67.3, 67.1, 67.1, $66.7,62.7,61.8,61.7,60.3,54.1,53.9,53.8,53.0,49.1,47.7,47.5,47.4,47.0,31.7,29.2$, 28.3, 23.2, 22.9, 22.9, 21.0, 20.9, 20.8, and 20.7. MS (EI) $\mathrm{m} / z$ 1593.7 [M+ Na] $]^{+}, 1605.6$ $[\mathrm{M}+\mathrm{Cl}]$, HRMS calcd for $\mathrm{C}_{69} \mathrm{H}_{90} \mathrm{~N}_{10} \mathrm{O}_{32}[\mathrm{M}+\mathrm{Na}]^{+}$1593.5620, found 1593.5592.

\section{Compound 11: $\operatorname{AcHN}-\left[\mathrm{Tn}(\mathrm{OAc})_{3}\right]_{3}-\mathrm{CONH}-\left(\mathrm{CH}_{2}\right)_{3}-\mathrm{N}_{3}$}

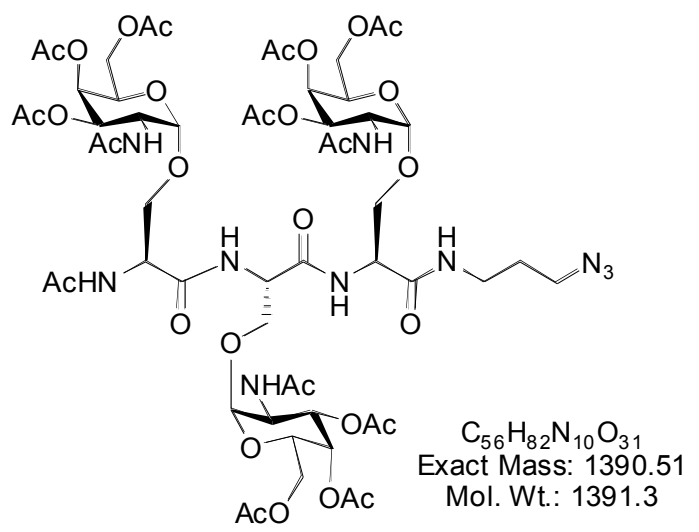

To the solution of $\mathbf{F m o c H N}-\left[\mathbf{T n}(\mathbf{O A c})_{3}\right]_{3}-\mathbf{C O N H}-\left(\mathbf{C H}_{2}\right)_{3}-\mathbf{N}_{\mathbf{3}}(\mathbf{1 0}, 109.0 \mathrm{mg}, 69.0 \mu \mathrm{mol})$ in DMF $(1.5 \mathrm{~mL})$, was added diethylamine $(30.0 \mu \mathrm{L})$. The reaction mixture was stirred at room temperature for overnight then $\mathrm{Ac}_{2} \mathrm{O}(60.0 \mu \mathrm{L})$ was added. After stirring for $3 \mathrm{~h}$, the reaction mixture was diluted with EtOAc, washed with brine- $\mathrm{H}_{2} \mathrm{O}$ (1:1). The organic phase was dried with $\mathrm{Na}_{2} \mathrm{SO}_{4}$, concentrated in vacuo. The residue was purified by silica gel column chromatography (3-5\% MeOH in $\mathrm{CH}_{2} \mathrm{Cl}_{2}$ ) to give the desired cluster $(\mathbf{1 1}, 92.0$ $\mathrm{mg}, 66.0 \mu \mathrm{mol}, 96 \%)$ as a white foam. $[\alpha]_{\mathrm{D}}^{21}=117.7\left(c 1.13, \mathrm{CHCl}_{3}\right)$; IR 3316, 3075, 2937, 2100, 1748, 1660, 1539, 1434, 1372, 1236, 1330, 1051, 917 and $732 \mathrm{~cm}^{-1} .{ }^{1} \mathrm{H} \mathrm{NMR}$ $\left(500 \mathrm{MHz}, \mathrm{CDCl}_{3}\right.$ ): $\delta 7.47$ (br, $\left.1 \mathrm{H}\right), 7.15$ (br, $\left.1 \mathrm{H}\right), 7.08$ (d, $1 \mathrm{H}, J=8.1 \mathrm{~Hz}$ ), 6.83 (br, 1 $\mathrm{H}), 6.59(\mathrm{~d}, 1 \mathrm{H}, J=9.1 \mathrm{~Hz}), 5.34(\mathrm{~d}, 1 \mathrm{H}, J=2.1 \mathrm{~Hz}), 5.33(\mathrm{~d}, 1 \mathrm{H}, J=2.9 \mathrm{~Hz}), 5.31(\mathrm{~d}$, $1 \mathrm{H}, J=2.4 \mathrm{~Hz}), 5.15(\mathrm{~m}, 1 \mathrm{H}), 5.11(\mathrm{dd}, 1 \mathrm{H}, J=11.5,3.0 \mathrm{~Hz}), 5.08(\mathrm{dd}, 1 \mathrm{H}, J=3.0$, $11.4 \mathrm{~Hz}), 4.94(\mathrm{~d}, 1 \mathrm{H}, J=3.2 \mathrm{~Hz}), 4.91(\mathrm{~d}, 1 \mathrm{H}, J=3.4 \mathrm{~Hz}), 4.87(\mathrm{~d}, 1 \mathrm{H}, J=3.5 \mathrm{~Hz})$, 4.75-4.45 (m, $5 \mathrm{H}), 4.21-4.10(\mathrm{~m}, 3 \mathrm{H}), 4.10-3.96(\mathrm{~m}, 5 \mathrm{H}), 3.94$ (dd, $1 \mathrm{H}, J=7.4,11.3$ $\mathrm{Hz}), 3.89(\mathrm{dd}, 1 \mathrm{H}, J=4.7,9.9 \mathrm{~Hz}), 3.81-3.72(\mathrm{~m}, 4 \mathrm{H}), 3.68(\mathrm{dd}, 1 \mathrm{H}, J=6.7,9.7 \mathrm{~Hz})$, 3.41-3.10 (m, 2 H), 3.11-3.02 (m, 2 H), 2.13 (m, 1 H), 2.12 (s, $3 \mathrm{H}), 2.11$ (s, $6 \mathrm{H}), 2.03$ (s, 
$3 \mathrm{H}), 2.02$ (s, $3 \mathrm{H}), 2.01(\mathrm{~s}, 6 \mathrm{H}), 1.98(\mathrm{~s}, 3 \mathrm{H}), 1.97$ (s, $3 \mathrm{H}), 1.96(\mathrm{~s}, 3 \mathrm{H}), 1.95(\mathrm{~s}, 3 \mathrm{H})$, $1.94(\mathrm{~s}, 3 \mathrm{H}), 1.92(\mathrm{~s}, 3 \mathrm{H})$ and $1.76(\mathrm{~m}, 2 \mathrm{H}) .{ }^{13} \mathrm{C} \mathrm{NMR}\left(125 \mathrm{MHz}, \mathrm{CDCl}_{3}\right): \delta 171.3$, 171.2 , 171.1, 170.9, 170.8, 170.7, 170.6, 170.5, 170.3, 169.8, 169.2, 169.1, 98.6, 98.3, $98.2,69.5,68.3,68.2,67.7,67.5,67.2,66.2,67.1,66.8,66.8,66.7,62.5,61.9,61.7,53.8$, 53.7, 53.1, 52.6, 49.1, 47.7, 47.6, 47.5, 37.4, 31.7, 30.9, 29.3, 28.3, 23.1, 23.0, 22.93, 22.89, 20.87, 20.80, 20.75 and 20.66. MS (EI) $\mathrm{m} / \mathrm{z} 1413.7[\mathrm{M}+\mathrm{Na}]^{+}, 1425.6[\mathrm{M}+\mathrm{Cl}]^{-}$, HRMS calcd for $\mathrm{C}_{56} \mathrm{H}_{83} \mathrm{~N}_{10} \mathrm{O}_{31}[\mathrm{M}+\mathrm{H}]^{+}$1391.5226, found 1391.5227.

\section{Compound 12: AcHN-[Tn $]_{3}-\mathrm{CONH}-\left(\mathrm{CH}_{2}\right)_{3}-\mathrm{N}_{3}$}

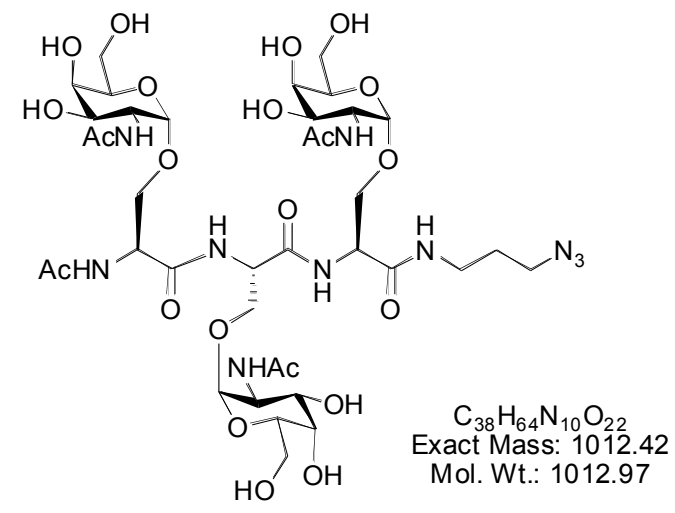

$\operatorname{AcHN}-\left[\mathbf{T n}(\mathbf{O A c})_{3}\right]_{3}-\mathbf{C O N H}-\left(\mathbf{C H}_{2}\right)_{3}-\mathbf{N}_{3}(\mathbf{1 1}, 90.0 \mathrm{mg}, 64.7 \mu \mathrm{mol})$ was dissolved in the solution of $\mathrm{NH}_{3}$ in $\mathrm{MeOH}(2.0 \mathrm{~mL}, 7 \mathrm{~N})$. The reaction mixture was stirred at room temperature for overnight and concentrated in vacuo. The residue was purified by HPLC (0-25\% solvent B/solvent A over $20 \mathrm{~min})$ gave desired compound (12, $50.0 \mathrm{mg}, 49.0$ $\mu \mathrm{mol}, 76 \%)$ as a white foam. ${ }^{1} \mathrm{H}$ NMR $\left(500 \mathrm{MHz}, \mathrm{D}_{2} \mathrm{O}\right): \delta 4.91(\mathrm{~m}, 3 \mathrm{H}), 4.72(\mathrm{t}, 1 \mathrm{H}, J=$ $5.6 \mathrm{~Hz}), 4.66(\mathrm{t}, 1 \mathrm{H}, J=5.6 \mathrm{~Hz}), 4.59(\mathrm{t}, 1 \mathrm{H}, J=5.5 \mathrm{~Hz}), 4.19(\mathrm{~m}, 3 \mathrm{H}), 4.02-3.91(\mathrm{~m}, 6$ $\mathrm{H}), 3.91-3.85(\mathrm{~m}, 6 \mathrm{H}), 3.83-3.71(\mathrm{~m}, 9 \mathrm{H}), 3.35(\mathrm{t}, 2 \mathrm{H}, J=6.6 \mathrm{~Hz}), 3.10(\mathrm{~m}, 2 \mathrm{H}), 2.07$ $(\mathrm{s}, 3 \mathrm{H}), 2.06(\mathrm{~s}, 3 \mathrm{H}), 2.06(\mathrm{~s}, 3 \mathrm{H}), 2.01(\mathrm{~s}, 3 \mathrm{H})$ and $1.78(\mathrm{ddd}, 2 \mathrm{H}, J=6.7,13.4 \mathrm{~Hz})$. ${ }^{13} \mathrm{C}$ NMR (125 MHz, $\mathrm{D}_{2} \mathrm{O}+$ trace of acetone): 175.3, 174.9, 174.9, 174.7, 171.9, 171.3, 171.3, 98.6, 98.5, 98.3, 71.9, 71.9, 68.9, 68.9, 68.3, 68.2, 67.8, 67.8, 67.7, 61.74, 61.67, $54.2,54.0,50.3,50.2,49.2,37.5,28.3,22.6$ and 22.2. MS (EI) $m / z 1013.29[\mathrm{M}+\mathrm{H}]^{+}$.

\section{Compound 13: AcNH-Ala-Lys-Arg-Tyr-Lys-Phe-Ala-Lys-Ser-Ala-NH}

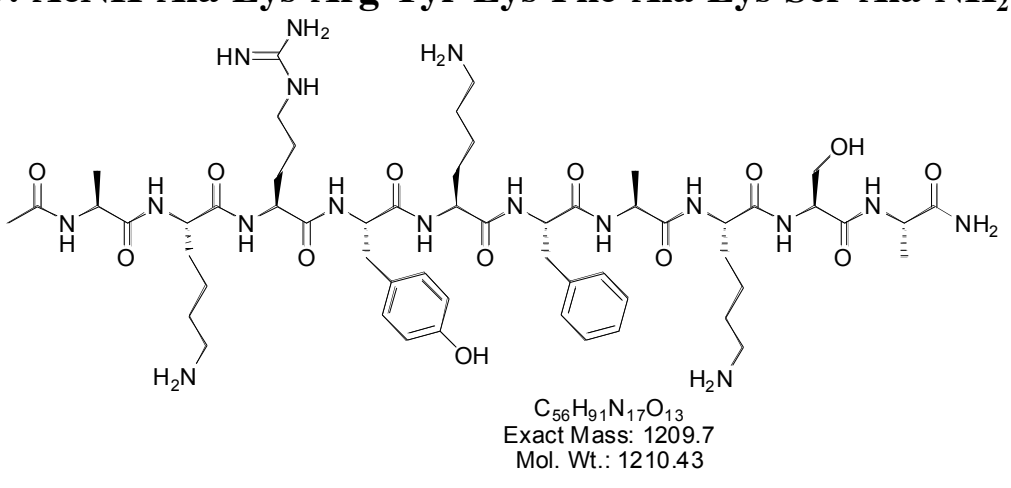


The peptide was prepared by standard solid phase synthesis with PAL-PEG-PS amine resin. The peptide was cleaved from resin by the use of $95 \%$ TFA with triethylsilane $(2.5 \%)$ and water $(2.5 \%)$. All the acid sensitive protecting groups on the side chain were removed too. And the peptide was purified with RP-HPLC (15-45\% solvent B / solvent A over $20 \mathrm{~min}$ ) to give the desired peptide 13.

\section{Compound 14:}

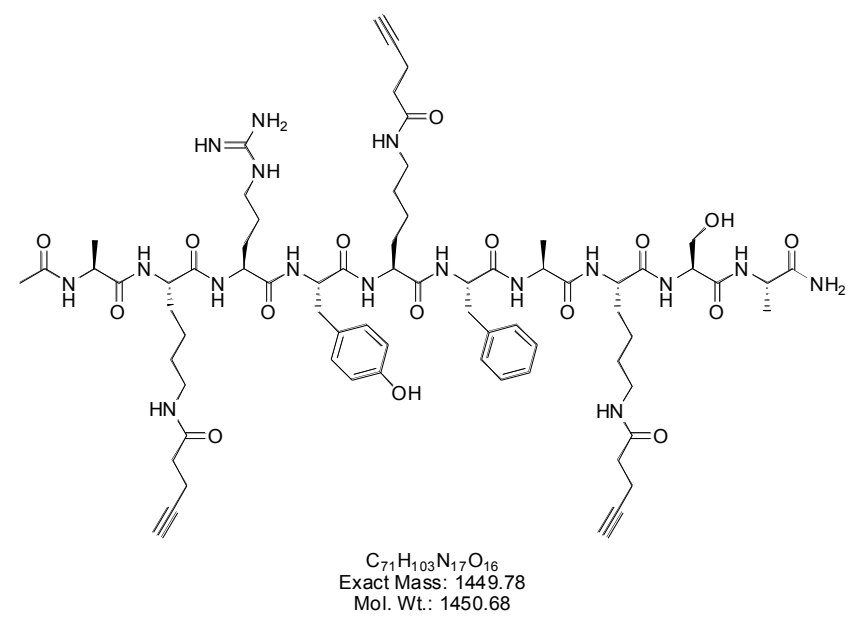

To the solution of AcNH-Ala-Lys-Arg-Tyr-Lys-Phe-Ala-Lys-Ser-Ala-NH $\mathbf{N H}_{\mathbf{2}}$ (13, 10.0 $\mathrm{mg}, 8.26 \mu \mathrm{mol})$ in $\mathrm{H}_{2} \mathrm{O}(1.0 \mathrm{~mL})$, was added the $0.4 \mathrm{~mL}$ of the solution of sodium bicarbonate $(5.0 \mathrm{mg} / 1.0 \mathrm{~mL})$ in $\mathrm{H}_{2} \mathrm{O}$ at room temperature. $N$-succinimido 4-pentynonate $(11.6 \mathrm{mg})$ was dissolved in DMF $(0.2 \mathrm{~mL})$ at room temperature. To the solution of peptide was added the solution of $N$-succinimido 4-pentynonate $(29.7 \mu \mathrm{mol}, 100.0 \mu \mathrm{L})$ in $\mathrm{DMF}$ at room temperature. The reaction mixture was stirred for $1 \mathrm{~h}$, and then $100.0 \mu \mathrm{L}$ of the solution of $\mathrm{NaHCO}_{3}$ was added. $19 \mathrm{~h}$ later, LC-MS (5-60\%, solvent B/solvent A over $20 \mathrm{~min}$ ) showed the reaction completed. To the reaction mixture, $1.5 \mathrm{~mL}$ of $0.04 \%$ TFA in water and $1.0 \mathrm{~mL}$ of $\mathrm{CH}_{3} \mathrm{CN}$ were added. The residue was purified by HPLC (0-25\% solvent $\mathrm{B} /$ solvent $\mathrm{A}$ over $20 \mathrm{~min}$, semi prep C18 column) gave desired compound (14, $8.2 \mathrm{mg}, 68 \%)$ as a white foam. Selected ${ }^{1} \mathrm{H}$ NMR (500 MHz, $\left.\mathrm{CD}_{3} \mathrm{OD}\right): \delta$ 7.30-7.19 $9(\mathrm{~m}$, $5 \mathrm{H}), 7.08(\mathrm{~d}, 1 \mathrm{H}, J=8.4 \mathrm{~Hz}), 7.03(\mathrm{~d}, 1 \mathrm{H}, J=8.4 \mathrm{~Hz}), 6.72(\mathrm{~d}, 1 \mathrm{H}, J=8.4 \mathrm{~Hz}), 6.71$ $(\mathrm{d}, 1 \mathrm{H}, J=8.4 \mathrm{~Hz})$. MS (EI) $\mathrm{m} / z$ 1450.91 [M+ H $]^{+}$. 


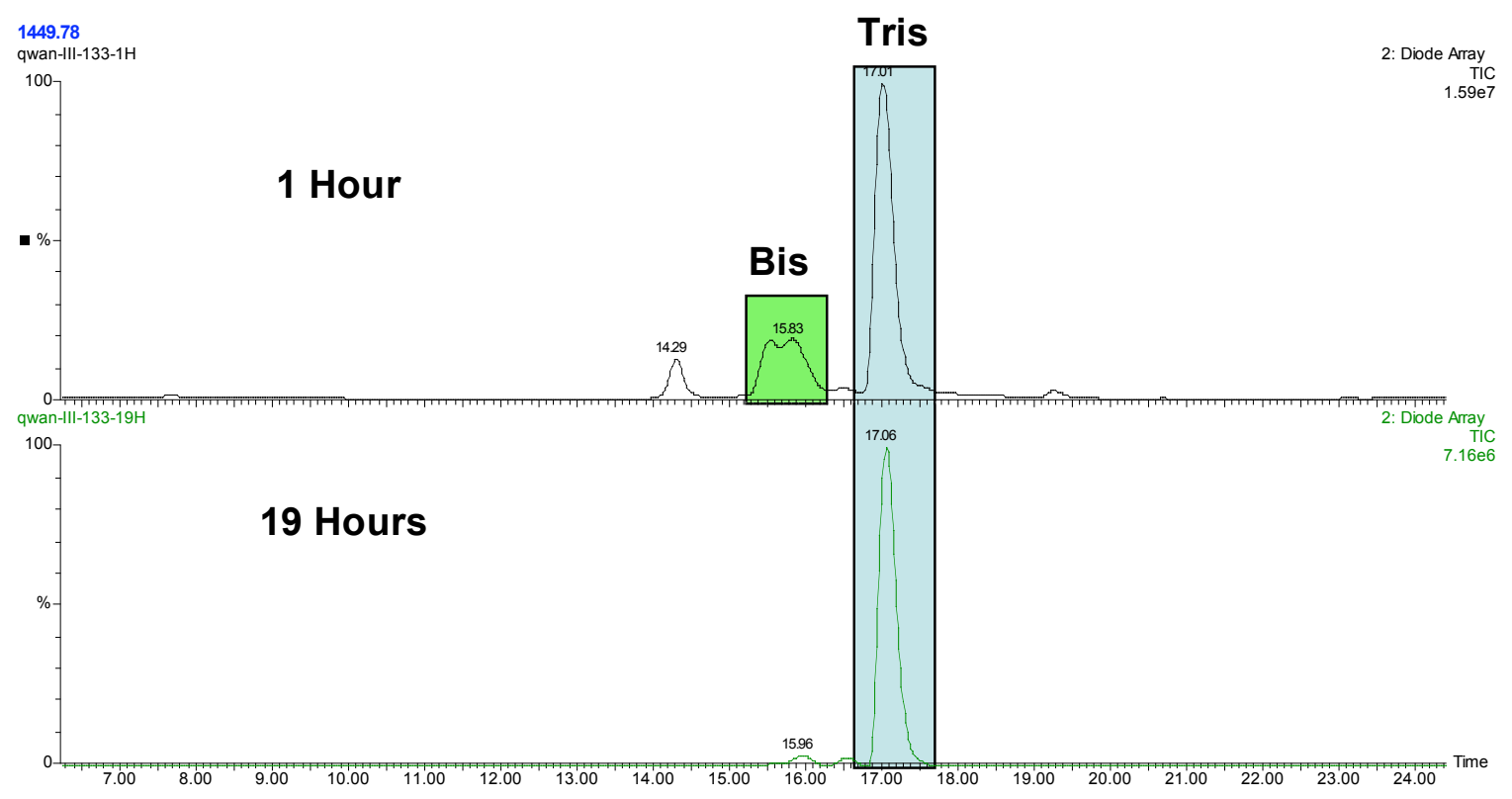

Figure 1: UV and MS traces of LC-Mass analysis of synthesis of compound 14.

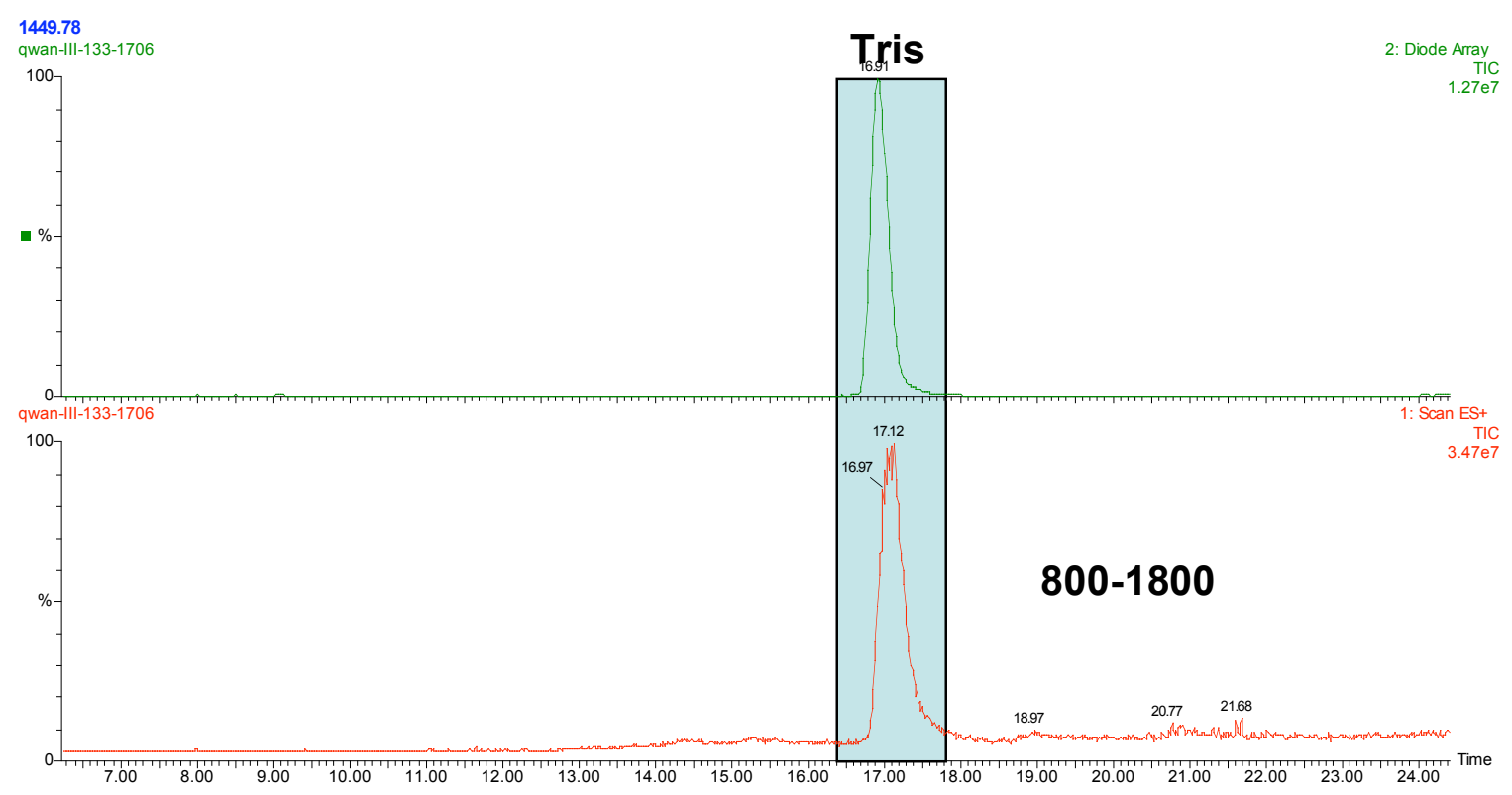

Figure 2: UV and MS traces of LC-Mass analysis of compound 14 after purification by HPLC 


\section{Compound 15:}

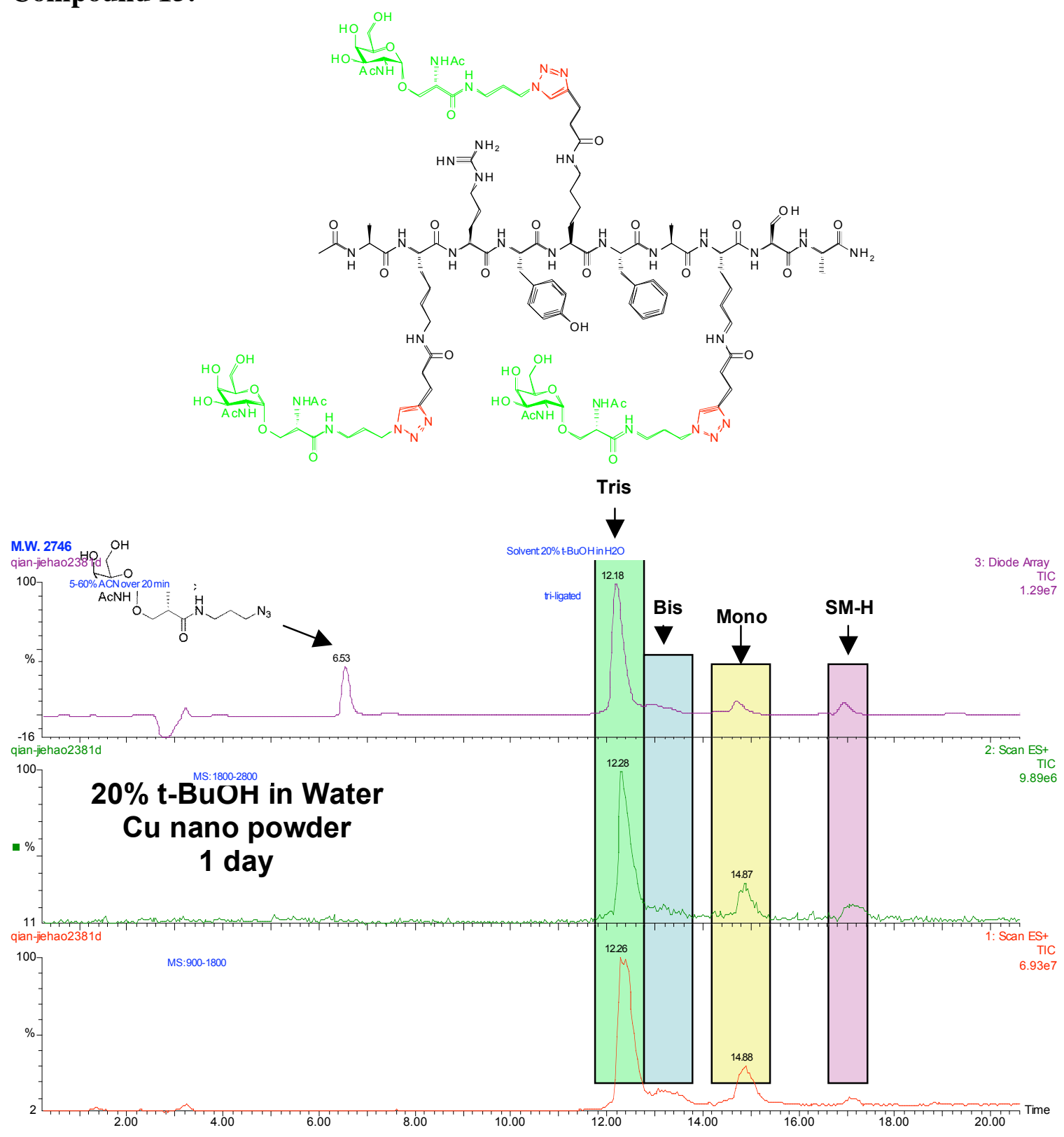

Figure 3: UV and MS traces of LC-Mass analysis of synthesis of compound $\mathbf{1 5 .}$ 


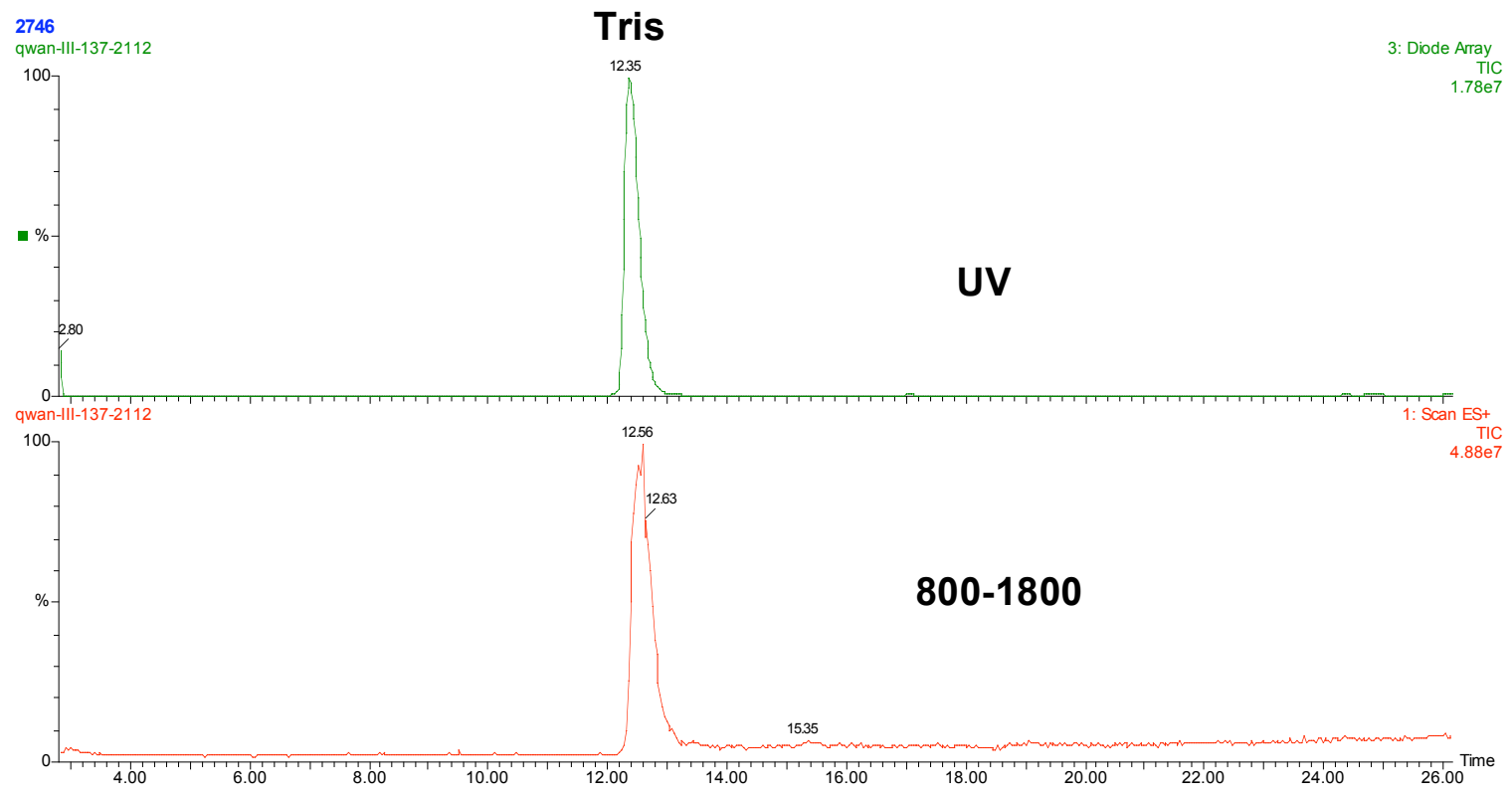

Figure 4: UV and MS traces of LC-Mass analysis of compound $\mathbf{1 5}$ after purification by HPLC

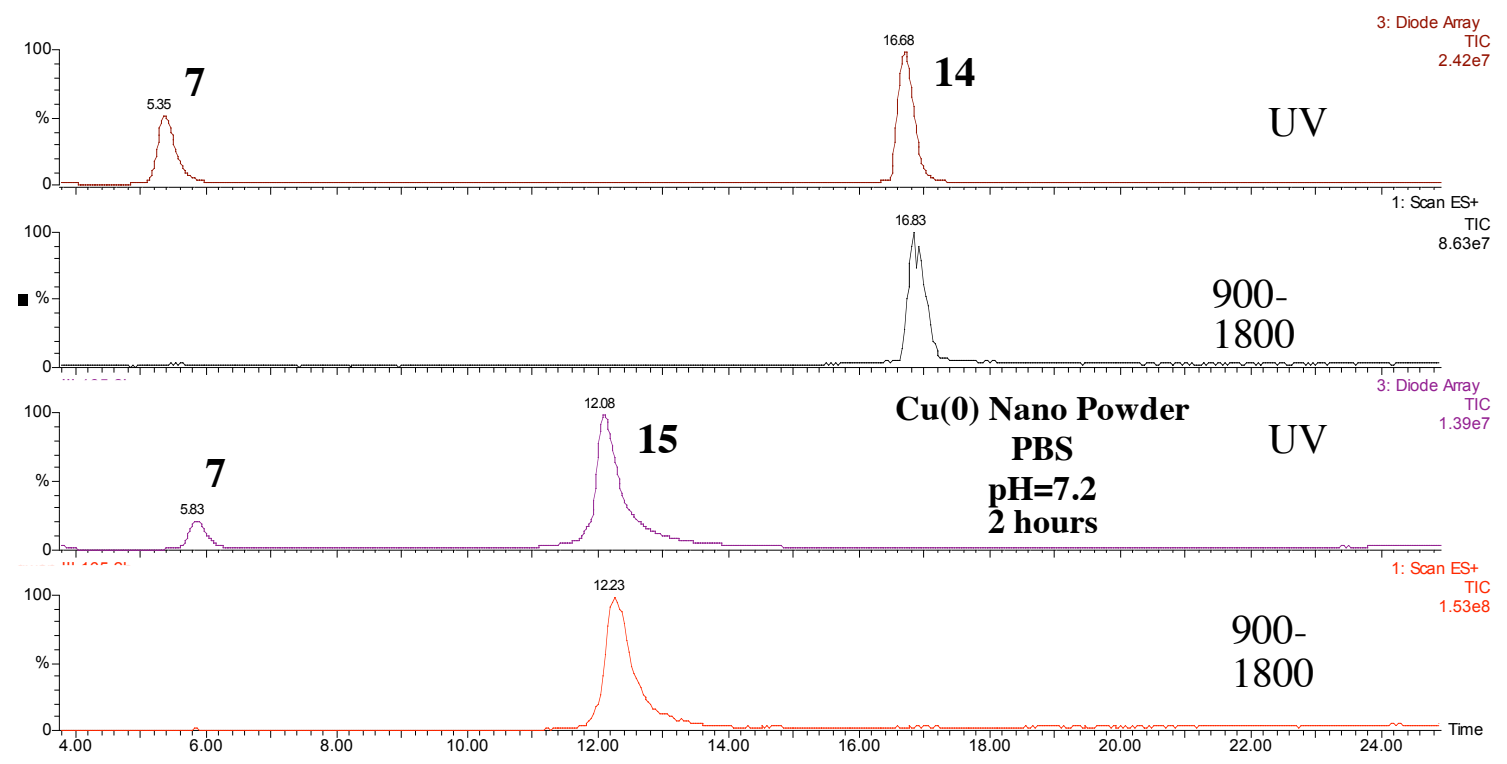

Figure 5: UV and MS traces of LC-Mass analysis of synthesis of compound $\mathbf{1 5 .}$

\section{Compound 16:}




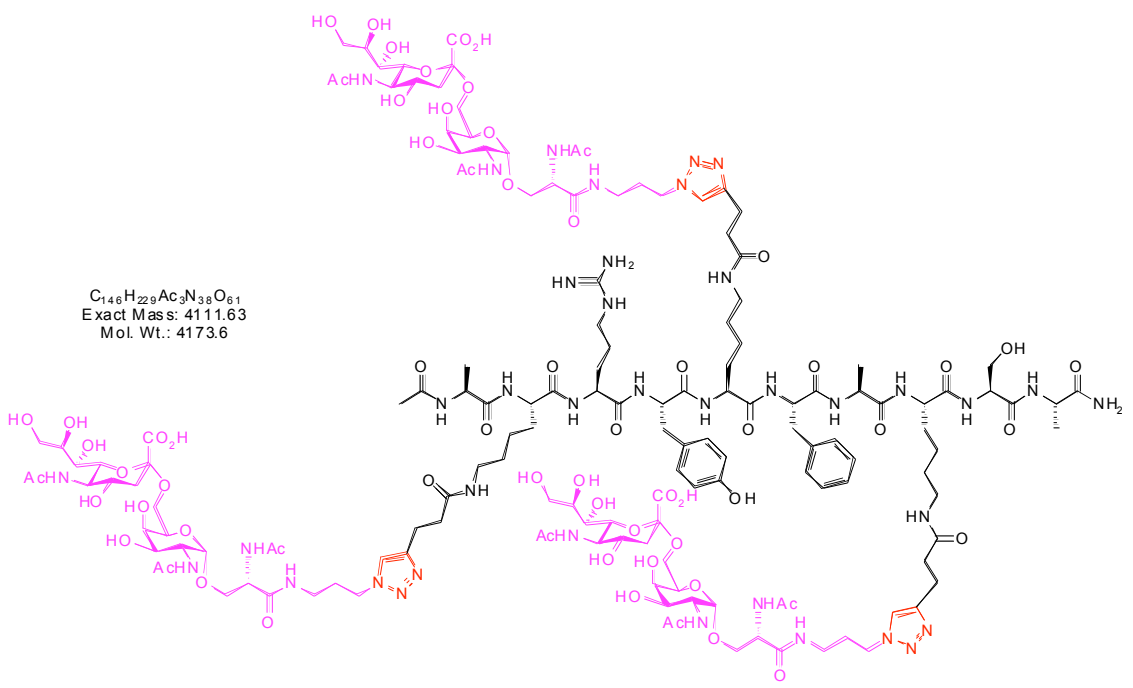

To a vial with peptide $\mathbf{1 4}(1.1 \mathrm{mg})$ and azide $\mathbf{8}(2.4 \mathrm{mg}, 4.5 \mathrm{eq})$ was added a solution of triethylamine hydrochloride ( $2.5 \mathrm{mg}$ in $2.5 \mathrm{~mL}$, pick up $0.15 \mathrm{~mL}$ ) and nanosized copper $(0.8 \mathrm{mg})$. After stirring at $\mathrm{rt}$ for $1 \mathrm{~h}$, analysis of LC-MS showed that all the three alkyne moieties were converted into triazoles. The reaction mixture was filtered and purified by RP-HPLC (5-60\% solvent B/solvent A over $20 \mathrm{~min}$, semi prep C18 column) to give the desired product (16, $2.1 \mathrm{mg}, 78 \%)$.

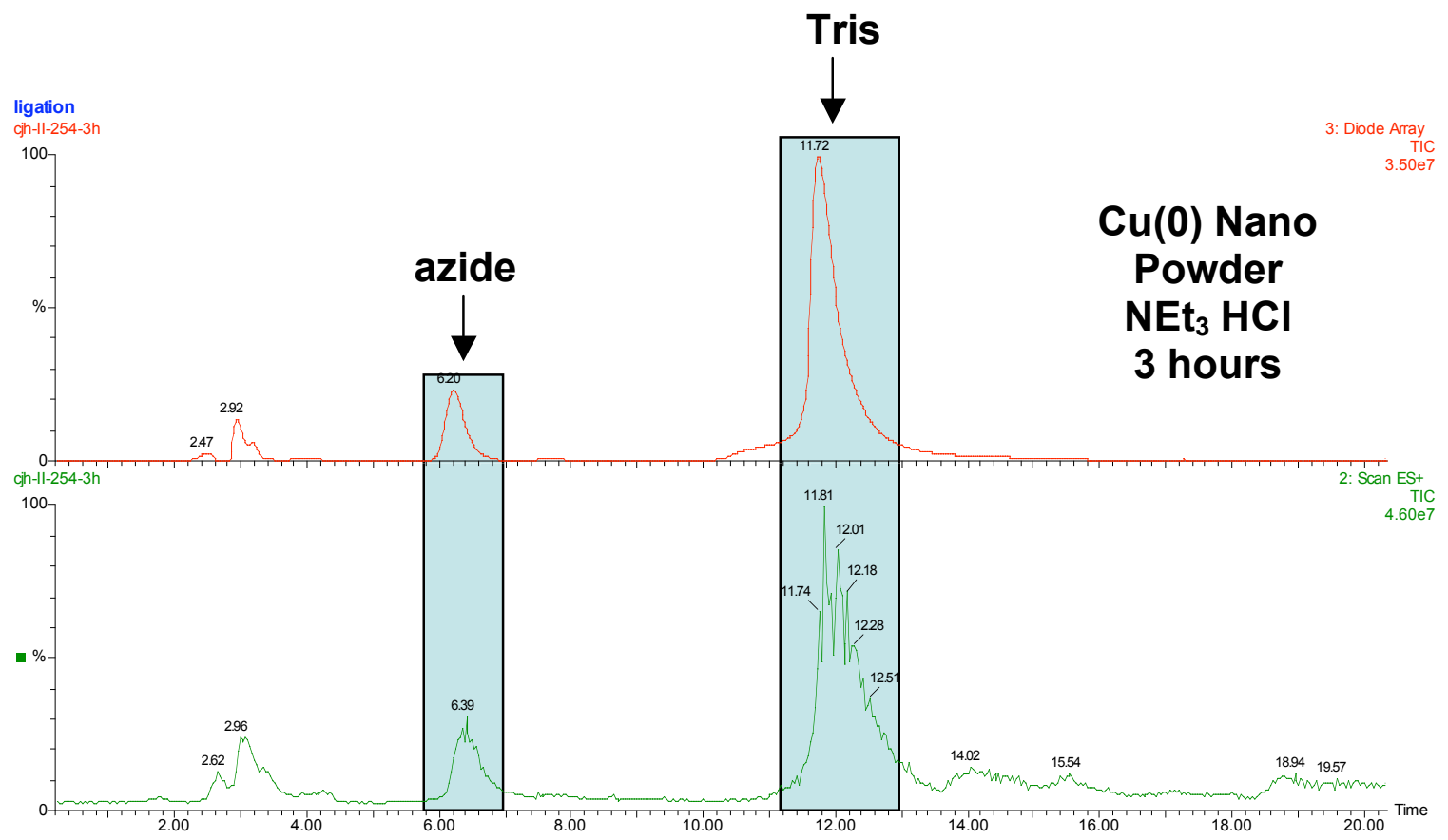

Figure 6: UV and MS traces of LC-Mass analysis of synthesis of compound $\mathbf{1 6 .}$

\section{Compound 17:}




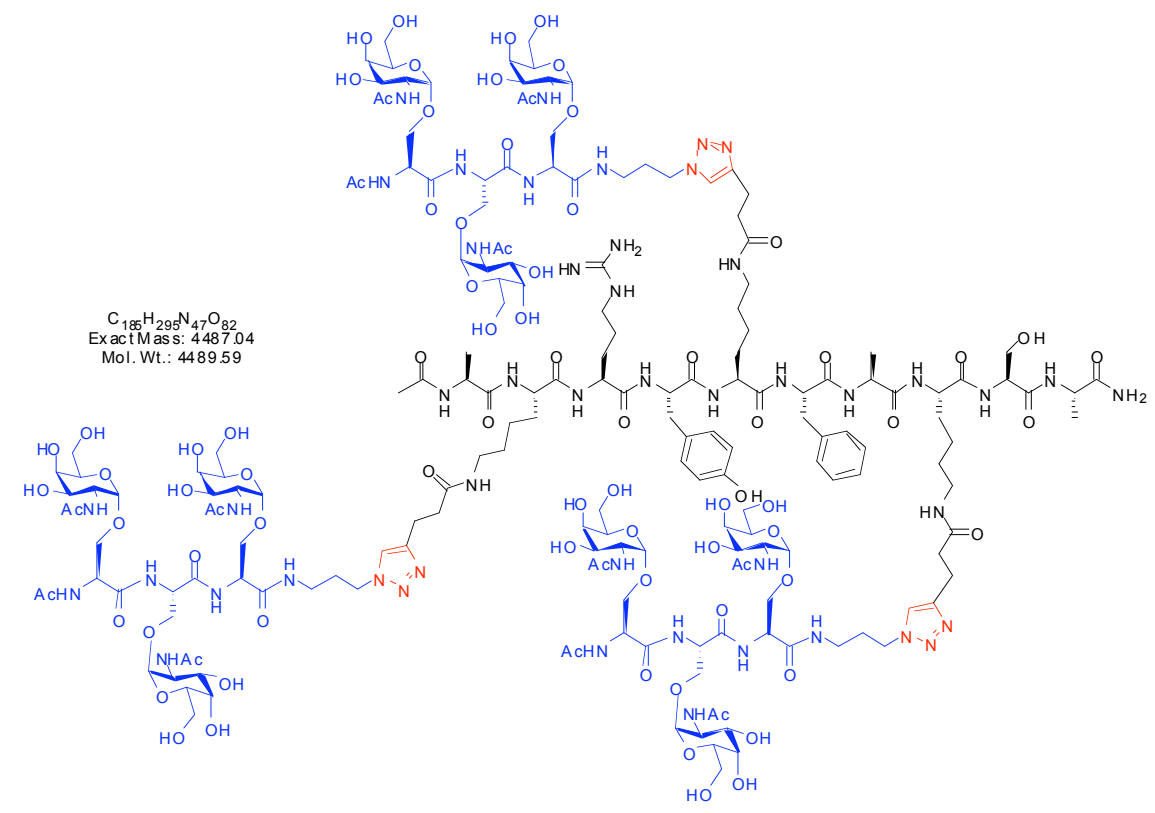

To a mixture of AcHN-[Tn] $]_{3}-\mathbf{C O N H}-\left(\mathbf{C H}_{2}\right)_{3}-\mathbf{N}_{3}(\mathbf{1 2}, 4.7 \mathrm{mg}, 4.65 \mu \mathrm{mol})$ and $\mathbf{1 4}(1.5 \mathrm{mg}$, $1.03 \mu \mathrm{mol})$, were added water $(200.0 \mu \mathrm{L}), t$ - $\mathrm{BuOH}(50 \mu \mathrm{L})$ and $\mathrm{Cu}(0)$ nanosize powder $(1.5 \mathrm{mg})$ at room temperature. The reaction mixture was stirred for 2 days, and then 0.5 $\mathrm{mg}$ of $\mathrm{Cu}(0)$ nanosize powder was added. The reaction mixture was stirred for one more day, and then centrifuged for $5 \mathrm{~min}$. The aqueous phase was removed, the $\mathrm{Cu}(0)$ was washed with $500.0 \mu \mathrm{L}$ of water and centrifuged. The aqueous phases were combined, and passed through $0.2 \mu \mathrm{m}$ filter. The light blue solution was purified by HPLC (5-50\% solvent $\mathrm{B} /$ solvent $\mathrm{A}$ over 20 min, semi prep C18 column) gave desired compound (17, $3.0 \mathrm{mg}, 0.67 \mu \mathrm{mol}, 65 \%)$ as a white powder. Selected ${ }^{1} \mathrm{H}$ NMR $\left(500 \mathrm{MHz}, \mathrm{D}_{2} \mathrm{O}\right): \delta 7.78$ (s, $2 \mathrm{H}), 7.77(\mathrm{~s}, 1 \mathrm{H}), 7.31(\mathrm{~m}, 2 \mathrm{H}), 7.23(\mathrm{~m}, 3 \mathrm{H}), 7.06(\mathrm{~d}, 2 \mathrm{H}, J=8.4 \mathrm{~Hz}), 7.79(\mathrm{~d}, 1$ $\mathrm{H}, J=8.4 \mathrm{~Hz}$ ) and $7.77(\mathrm{~d}, 1 \mathrm{H}, J=8.4 \mathrm{~Hz})$. MS (EI) $\mathrm{m} / z 2245.26[\mathrm{M}+2 \mathrm{H}]^{++}, 1497.27$ $[\mathrm{M}+3 \mathrm{H}]^{+++}$. 


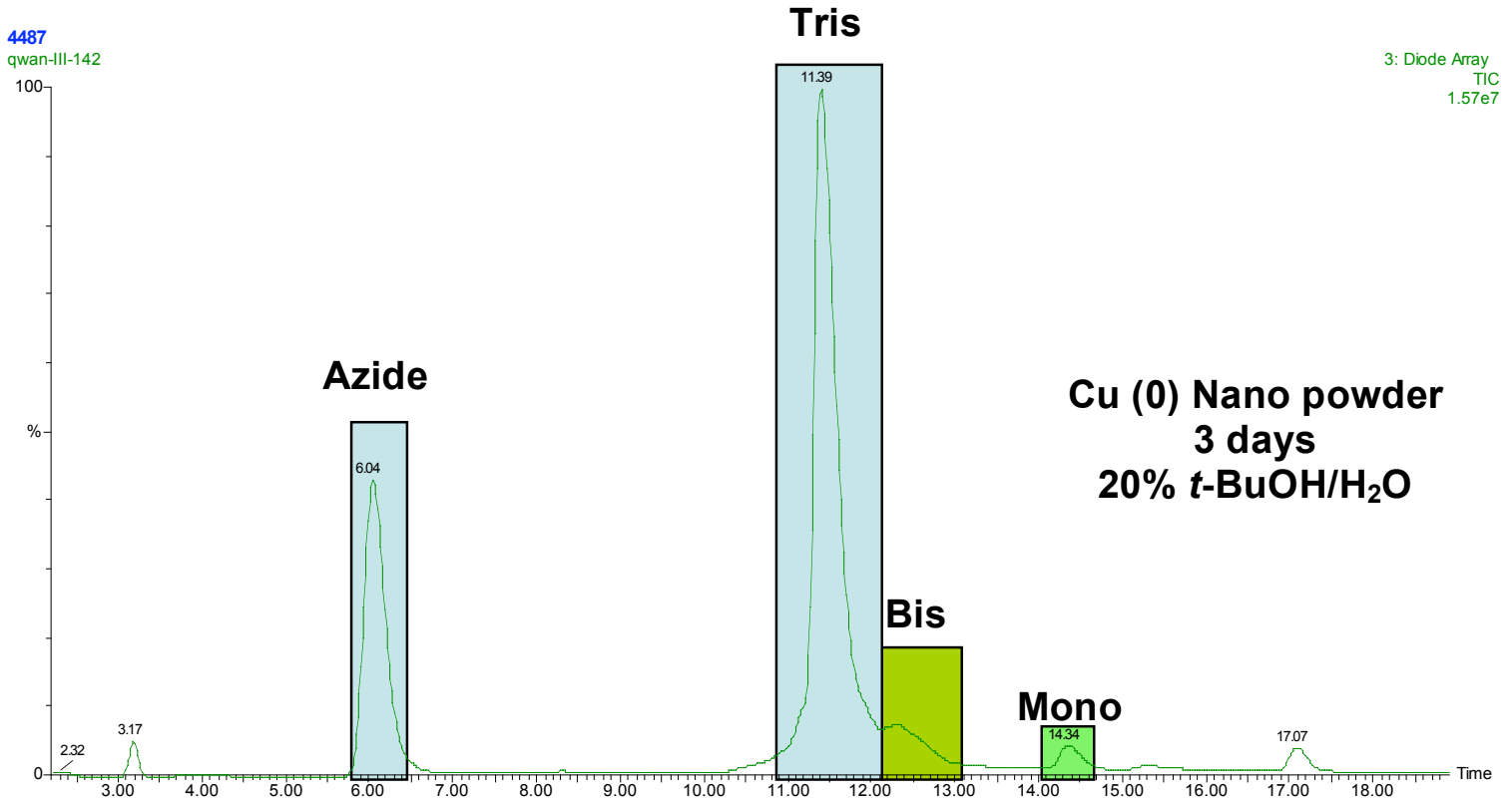

Figure 7: UV and MS traces of LC-Mass analysis of synthesis of compound 17.

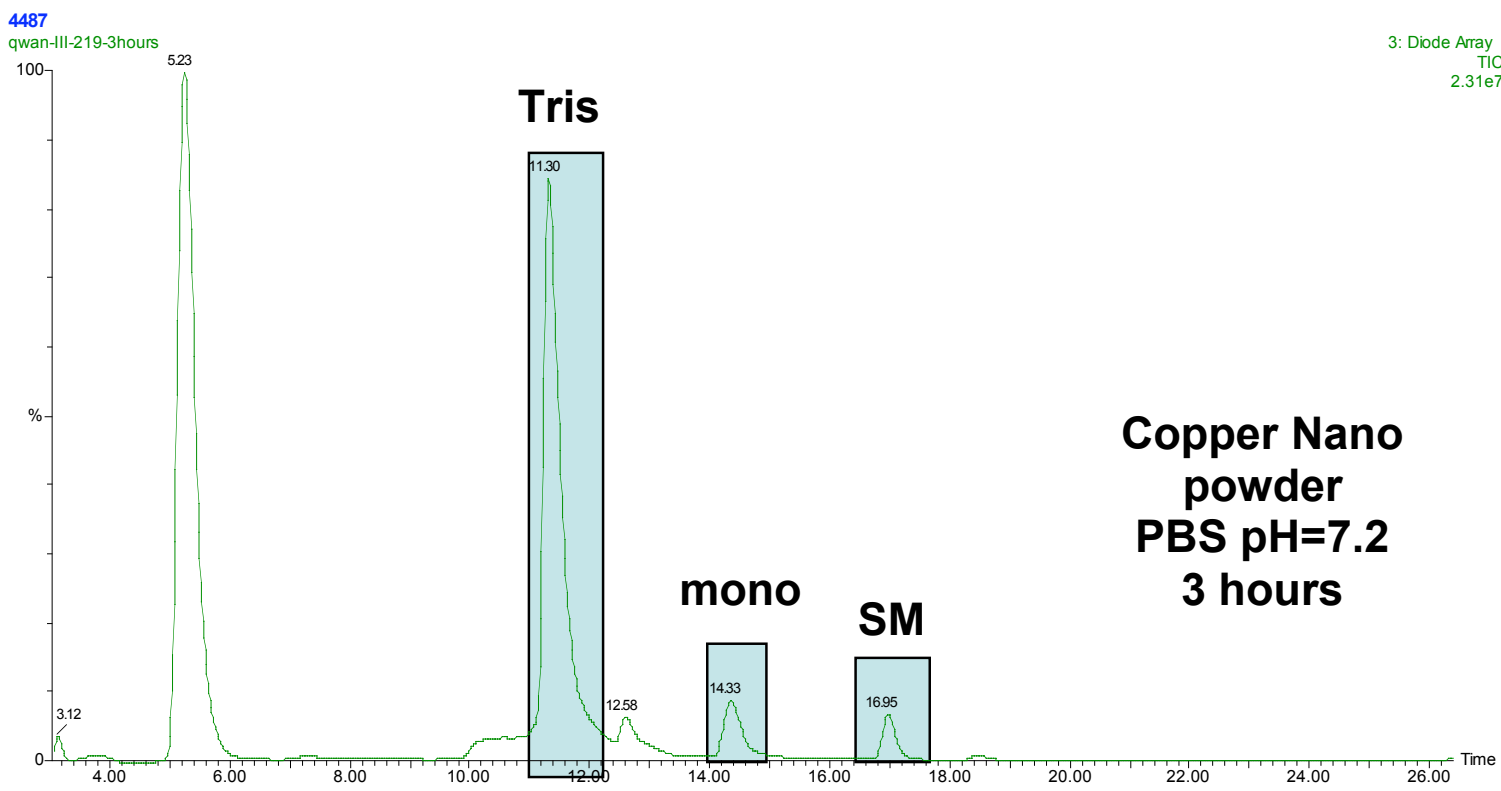

Figure 8: UV and MS traces of LC-Mass analysis of synthesis of compound $\mathbf{1 7 .}$ 


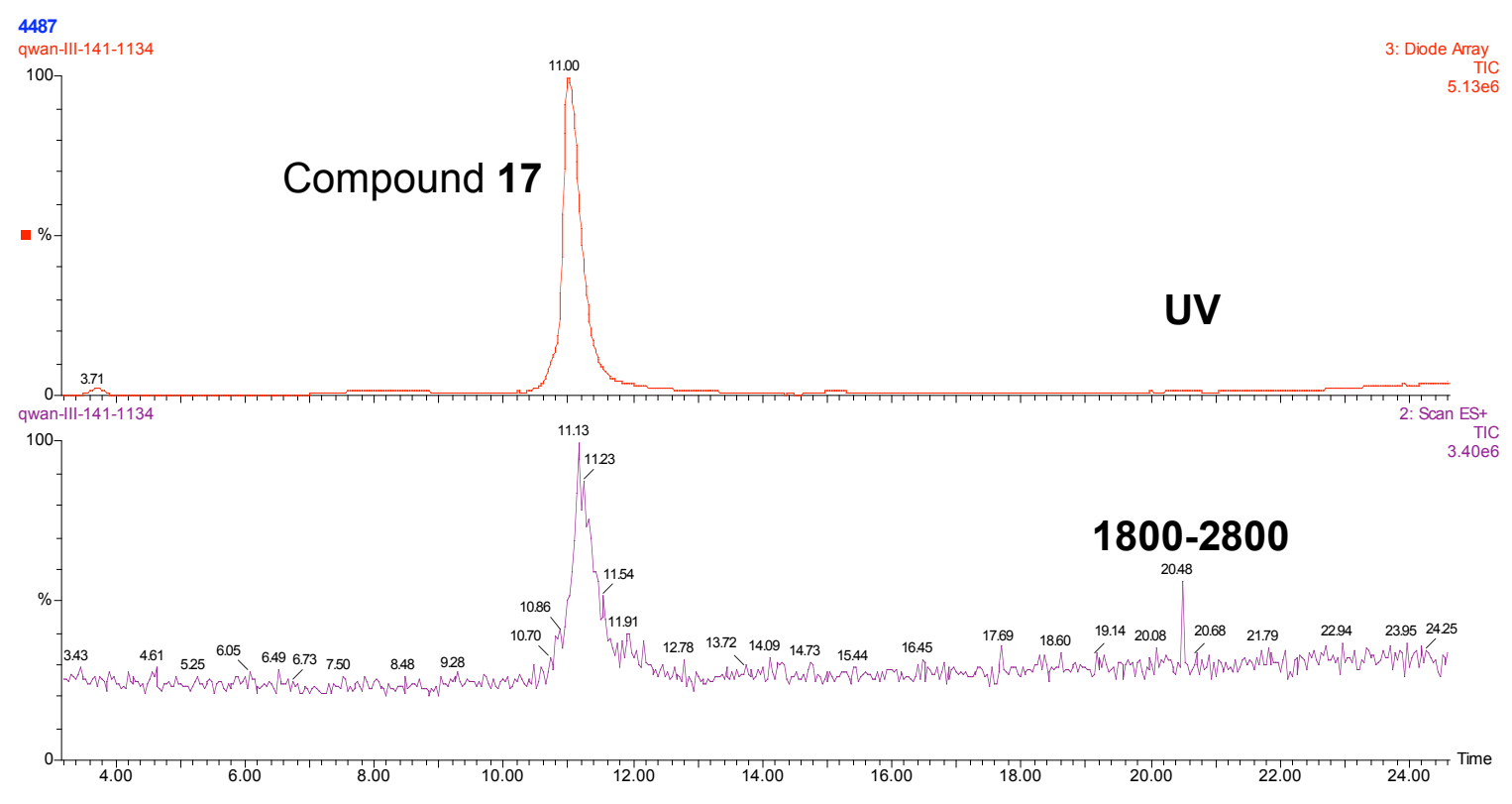

Figure 9: UV and MS traces of LC-Mass analysis of compound $\mathbf{1 7}$ after purification by HPLC

\section{Compound 19:}

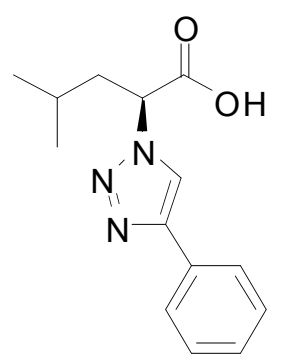

To a solution of phenylacetylene $(78.5 \mu \mathrm{L}, 0.72 \mathrm{mmol})$ and azido-Leu $(75.0 \mathrm{mg}, 0.48$ $\mathrm{mmol}), \mathbf{1 8}$, in $t$ - BuOH $(0.1 \mathrm{~mL})$ and PBS buffer $(0.1 \mathrm{~mL})$ was added $\mathrm{Cu}(0)$ nano powder (3.0 mg, $0.1 \mathrm{eq})$. The reaction mixture was stirred at room temperature for overnight. The reaction mixture was diluted with EtOAc, and filtered by silical gel. The organic phase was dried with $\mathrm{Na}_{2} \mathrm{SO}_{4}$, concentrated in vacuo. The residue was purified by silica gel column chromatography $\left(5 \% \mathrm{MeOH}\right.$ and $0.05 \% \mathrm{AcOH}$ in $\left.\mathrm{CH}_{2} \mathrm{Cl}_{2}\right)$ to give the desired trimer (19, $112.0 \mathrm{mg}, 0.47 \mathrm{mmol}, 98 \%)$ as a white solid. IR 2960, 1735, 1463, 1240, 1198, 1087, 977, 765 and $697 \mathrm{~cm}^{-1} ;{ }^{1} \mathrm{H}$ NMR (500 MHz, CD $\left.\mathrm{OD}\right): \delta 8.49(\mathrm{~s}, 1 \mathrm{H}), 7.84(\mathrm{~d}, 2 \mathrm{H}$, $J=7.7 \mathrm{~Hz}), 7.43(\mathrm{t}, 2 \mathrm{H}, J=7.7 \mathrm{~Hz}), 7.34(\mathrm{t}, 1 \mathrm{H}, J=7.7 \mathrm{~Hz}), 5.52(\mathrm{dd}, 1 \mathrm{H}, J=4.3,11.0$ $\mathrm{Hz}), 2.30(\mathrm{~m}, 1 \mathrm{H}), 2.12(\mathrm{~m}, 1 \mathrm{H}), 1.39(\mathrm{~m}, 1 \mathrm{H}), 1.04(\mathrm{~d}, 3 \mathrm{H}, J=6.5 \mathrm{~Hz}), 0.95(\mathrm{~d}, 3 \mathrm{H}, J$ $=6.5 \mathrm{~Hz}) .{ }^{13} \mathrm{C}$ NMR $\left(125 \mathrm{MHz}, \mathrm{CD}_{3} \mathrm{OD}\right): \delta 172.2,149.1,131.8,130.1,129.5,126.8$, 122.3, 63.1, 41.7, 26.2, 23.2 and 21.6. MS (EI) $\mathrm{m} / z$ 260.1 [M+H] $]^{+}, 257.8[\mathrm{M}-\mathrm{H}]^{-}$; HRMS calcd for $\mathrm{C}_{14} \mathrm{H}_{17} \mathrm{~N}_{3} \mathrm{O}_{2}[\mathrm{M}+\mathrm{H}]^{+} 260.1399$, found 260.1402 . 